\title{
Case report: paravalvular leak as a complication of percutaneous catheter ablation for atrial fibrillation
}

\author{
Orcun Gurbuz ${ }^{1 *}$, Abdulkadir Ercan, Hakan Ozkan², Gencehan Kumtepe ${ }^{1}$, Ilker H Karal ${ }^{3}$ and Serdar Ener ${ }^{4}$
}

\begin{abstract}
An increasing number of reports reveal the safety and efficacy of catheter ablation for atrial fibrillation therapy even in patients with a history of prosthetic heart valve. This case report presents a 60 year old female patient who had a prosthetic mitral paravalvular leak as a complication of radiofrequency ablation. Surgery revealed a $15 \mathrm{~mm}$ hole and three broken knots in the posterolateral mitral annulus. This report demonstrates radiofrequency ablation for atrial fibrillation in patients with prosthetic mitral valve may cause a paravalvular leak likely as a result of thermal injury. Moreover, patient can be asymptomatic at first. The clinician should keep in mind such complication and the patient should be evaluated in terms of paravalvular leakage.
\end{abstract}

Keywords: Paravalvular leak, Percutaneous catheter ablation, Prosthetic heart valve

\section{Background}

Since its first description in 1982 [1], radio frequency catheter ablation (RFA) has evolved to its present role as first-line therapy for most supraventricular arrhythmias [2-6]. The growing acceptance of this procedure has been brought about by an increasing number of reports revealing the safety and efficacy of catheter ablation for atrial fibrillation (AF) therapy. Reported complications of RFA include stroke, pericardial tamponade, valvular injury, pulmonary embolism, atrio-esophageal fistula and significant pulmonary vein (PV) stenosis [4-6]. We report the case of a patient with a history of mechanical mitral valve replacement (MVR) who had a paravalvular leak as a complication of RFA for AF therapy. This case is presented in order to draw attention to this rare presentation which has never been previously reported in the medical literature.

\section{Case presentation}

A sixty-year-old woman with the posterolateral prosthetic paravalvular leak (PVL) was referred to our clinic for surgical repair. She had a history of closed mitral

\footnotetext{
* Correspondence: gurbuzorcun@gmail.com

'Department of Cardiovascular Surgery, Balikesir University, School of Medicine, Balikesir 10010, Turkey

Full list of author information is available at the end of the article
}

commissurotomy 47 years ago, a prosthetic mitral valve replacement (MVR) in 1975 and a redo MVR in 2005 due valve dysfunction by pannus formation. Moreover, 1 years ago, she had undergone a pulmonary vein isolation (PVI), left atrium and mitral isthmus roof lines ablations for symptomatic persistent AF in another hospital, using CARTO mapping system (Biosense, Diamond Bar, CA, USA) and an irrigation ablation catheter (Biosense, ThermoCool SF Catheter, USA). Furthermore, RFA was delivered at pulmonary veins for up to $30 \mathrm{~W}$ and at both lines up to $35 \mathrm{~W}$ with a temperature limitation of $50 \mathrm{C}$. Despite successful conversion to sinus rhythm she developed progressive cardiac failure in months. Third month later, after the percutaneous ablation, she was classified as decompensating heart failure in New York Heart Association (NYHA) stage four. Transthoracic echocardiography revealed a moderate PVL with an ejection fraction of $60 \%$. Transesophageal echocardiography (TEE) demonstrated moderate to severe posterolateral prosthetic PVL (Figure 1). She was referred for surgery as she refused percutaneous closure of PVL. This patient was under echocardiography follow-up every three months, which were not revealed any PVL or pulmonary hypertension before the procedure, but three months after the RFA. After hospitalization, she underwent a coronary angiography, which revealed no obstructive lesions in coronary arteries. 


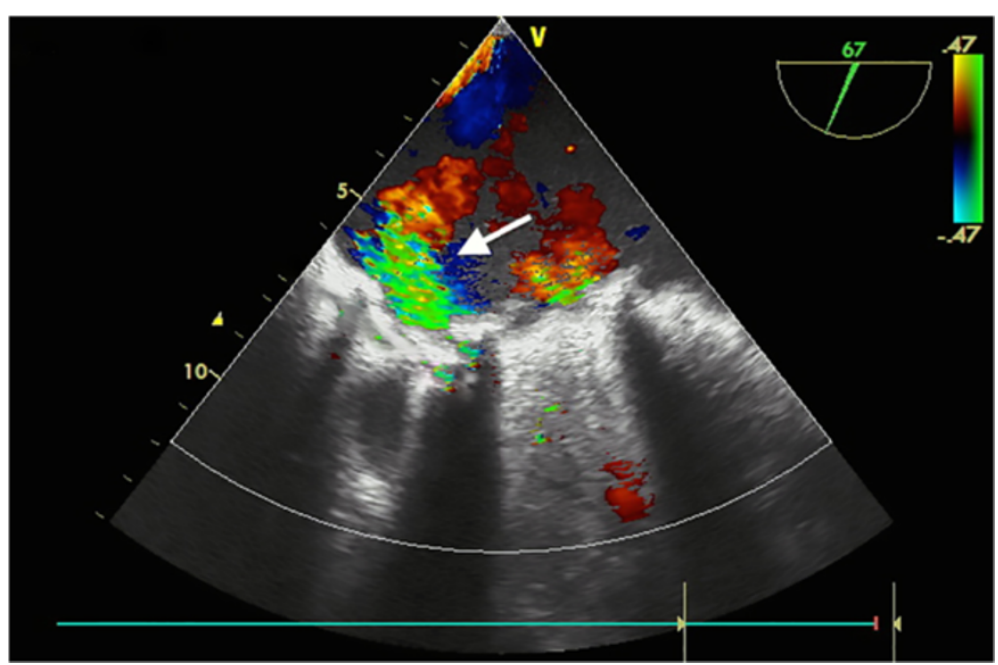

Figure 1 Transesophageal echocardiography illustrating paravalvular mitral regurgitation. Arrow indicates paravalvular leakage.

Following a full-resternotomy, pericardial adhesions were separated by sharp dissection, then cardiopulmonary bypass was initiated by aortic and bicaval venous cannulation. Systemic temperature was actively cooled down to $32 \mathrm{C}$. Following aortic cross-clamping, myocardial protection was achieved with antegrade and retrograde cold blood cardioplegia. The left atrium was reached by transseptal approach. A $15 \mathrm{~mm}$ defect was detected between mechanical valve and posterolateral mitral annulus where knot of 3 sutures was found to be broken (Figure 2). The defect was successfully repaired using separated 2-0 pledgeted sutures (Figure 3). İmmediately before declamping hot shot solution was administered. After declamping the heart was in nodal rhythm, therefore $5 \mathrm{mcg} / \mathrm{kg} / \mathrm{min}$ dopamine infusion and VVI pacing via 2 epicardial pacing leads was initiated. Cardiopulmonary bypass ended 50 minutes after its initiation. İntraoperative control TEE did not reveal any PVL and patient was transferred to the intensive care unit (ICU). She was extubated within 12 hours and dopamine infusion was stopped. On the second postoperative day, normal sinus rhythm returned and she was transferred out of the ICU. On the fourth postoperative day atrial fibrillation occurred which was converted into sinus rhythm by amiodarone. The patient was successfully

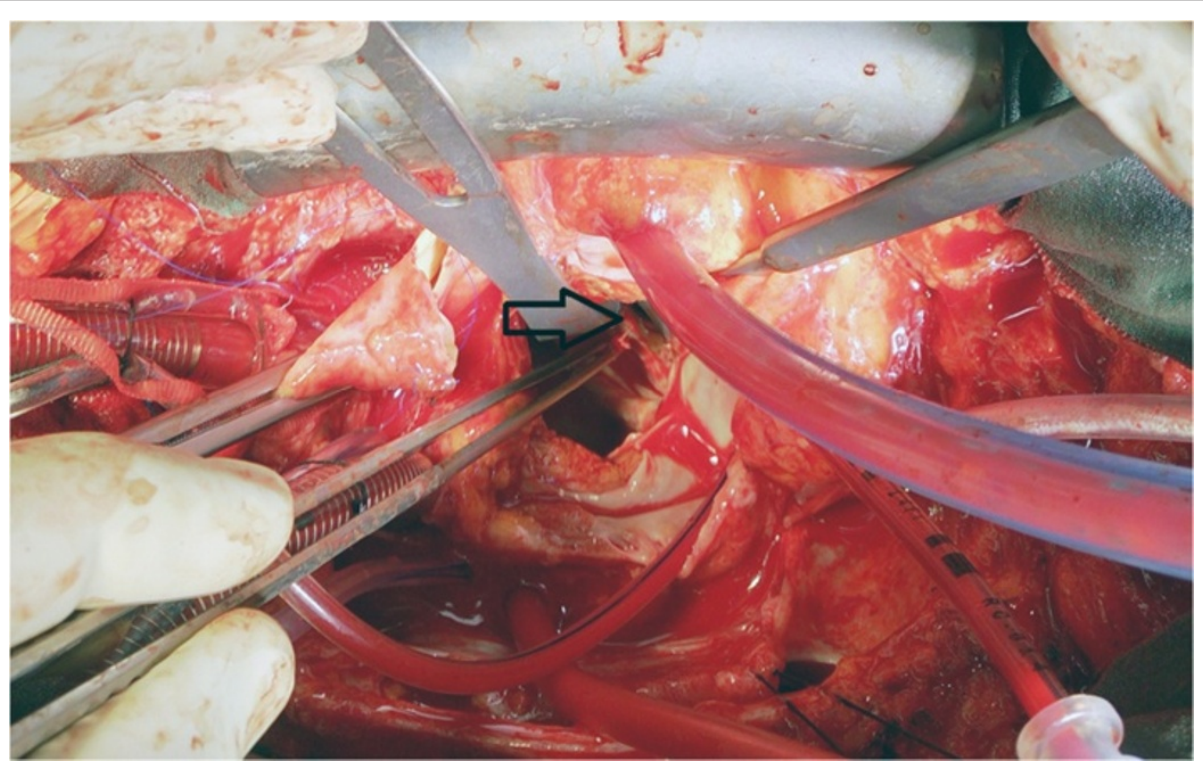

Figure 2 Perioperative image of paravalvular leak area. Arrow indicates paravalvular leakage area. 


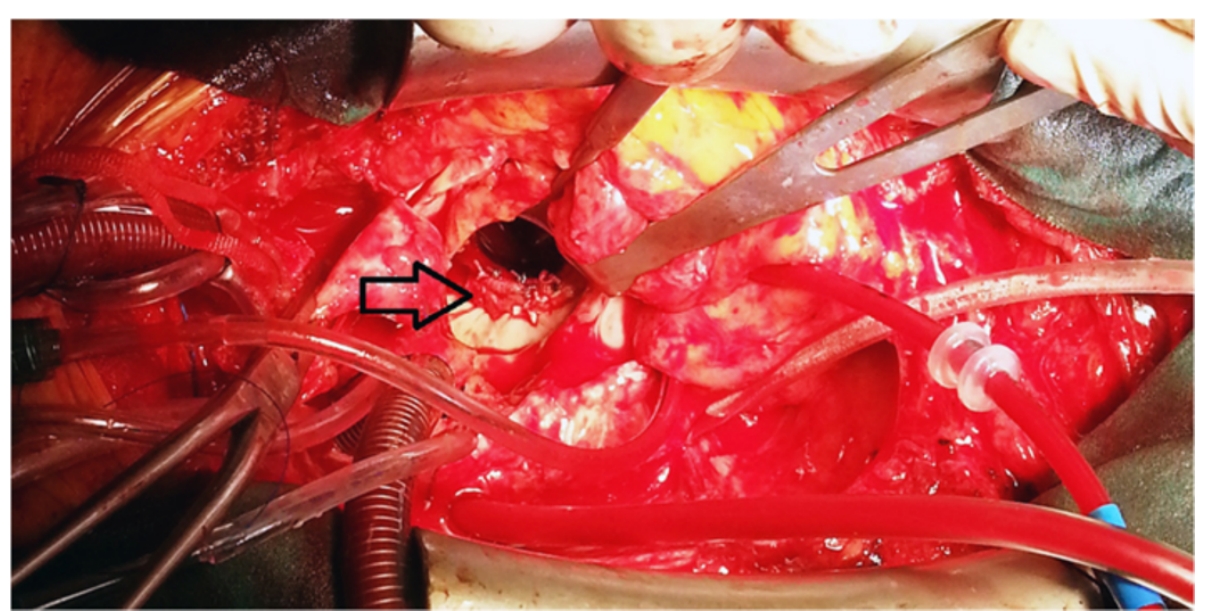

Figure 3 Periopertive image of repaired paravalvular leak area. Arrow indicates repaired paravalvular leakage.

discharged on the 7th day postoperatively in sinus rhythm and completed the 1-year follow-up without complications.

\section{Discussion}

Atrial fibrillation is the most common cardiac rhythm disturbances, with a prevalence estimated at $0.5 \%$ of the population [7]. It frequently arises from an abnormal focus near the junction of the pulmonary veins and the left atrium.

RFA is a widely used technique as a first-line therapy for a variety of supraventricular arrhythmias with a low incidence of complication. Studies generally report short-term recurrence rates up to $30 \%$, requiring repeat ablations. Moreover, if early recurrence does not occur longer-term recurrence rates are reported lower, in the range of $1-2 \%$ per year [8,9]. American Heart Association (AHA) suggests catheter ablation in patient with symptomatic paroxysmal AF or selected patients with symptomatic persistent AF [10].

Serious complications, including cardiac tamponade, pulmonary embolism, inferior myocardial infarction, significant PV stenosis or PV thrombosis, valvular injury, atrio-esophageal fistula and stroke are likely in the $1 \% 5 \%$ range.

Our report reveals PVL as a complication of this procedure in a patient with recent prosthetic mitral valve replacement. PVL is a well-known complication of prosthetic valve implantation, with an estimated incidence of $3 \%$ to $6 \%$ [11]. PVL can be asymptomatic or can have significant clinical consequence, such as congestive heart failure, hemolytic anemia, and infective endocarditis. Clinical success rates of percutaneous PVL repair approach $80 \%$ to $90 \%$ in selected patients [11].

Recent reports revealed favorable outcomes of RFA for atrial fibrillation therapy in patients with previous MVR. Moreover, PVL has never been previously reported after RFA [12,13].
Our report shows that during the RFA of left atrium, suture knots can be damaged by catheter induced thermal injury and PVL might develop. Interestingly, this complication has not been noticed immediately after treatment, but just after the development of heart failure.

\section{Conclusion}

Radiofrequency ablation for atrial fibrillation in patients with prosthetic mitral heart valve may cause a paravalvular leak which can be asymptomatic at first. The clinician should keep in mind such complication and the patient should be evaluated in terms of paravalvular leakage.

\section{Consent}

Written informed consent was obtained from the patients for publication of this case report and all accompanying images.

\section{Abbreviations}

AF: Atrial fibrillation; AHA: American heart association; ICU: Intensive care unit; MVR: Mitral valve replacement; NYHA: New york heart association; PVL: Paravalvular leak; PV: Pulmonary vein; RFA: Radio frequency catheter ablation; TEE: Transesophageal echocardiography.

\section{Competing interests}

The authors declare that they have no competing interests.

\section{Authors contributions}

All authors participated in the design of the case report and coordination and helped to draft the manuscript. All authors read and approved the final manuscript.

\section{Acknowledgements}

We thank Ozlem Sag r and Ayse Neslihan Balkaya, M.D s of Department of Anesthesiology, Bal kesir University for helping the patient s management.

\section{Disclosures}

The authors have no funding, financial relationships or conflicts of interest to disclose. 


\section{Author details}

${ }^{1}$ Department of Cardiovascular Surgery, Balikesir University, School of Medicine, Balikesir 10010, Turkey. ²Department Of Cardiology, Bahcesehir University Faculty of Medicine, Istanbul, Turkey. ${ }^{3}$ Department of Cardiovascular Surgery, Samsun Hospital for Education and Research, Samsun, Turkey. ${ }^{4}$ Department of Cardiovascular Surgery, Ac badem Bursa Hospital, Bursa, Turkey.

Received: 1 August 2014 Accepted: 20 November 2014

Published online: 17 December 2014

\section{References}

1. Critelli G: Catheter technique for closed-chest ablation of the atrioventricular conduction system: a therapeutic alternative for the treatment of refractory supraventricular tachycardia. N Engl J Med 1982, 306:194 200.

2. Kay GN, Epstein AE, Dailey SM, Plumb VJ: Role of radiofrequency ablation in the management of supraventricular arrhythmias: experience in 760 consecutive patients. J Cardiovasc Electrophysiol 1993, 4:371 389.

3. Calkins H, Yong P, Miller JM, Olshansky B, Carlson M, Saul JP, Huang SK, Liem LB, Klein LS, Moser S, Bloch D, Gillette P, Prystowsky E, the Atakr Multicenter Investigations Group: Catheter ablation of accessory pathways, atrioventricular nodal reentrant tachycardia, and the atrioventricular junction: final results of a prospective multicenter clinical trial. Circulation 1999, 99:262 270.

4. Vasamreddy CR, Lickfett L, Jayam VK, Nasir K, Bradley DJ, Eldadah Z, Dickfeld $\mathrm{T}$, Berger $\mathrm{R}$, Calkins $\mathrm{H}$ : Predictors of recurrence following catheter ablation of atrial fibrillation using an irrigated-tip ablation catheter. J Cardiovasc Electrophysiol 2004, 15:692 697

5. Oral H, Scharf C, Chugh A, Hall B, Cheung P, Good E, Veerareddy S, Pelosi F $\mathrm{Jr}$, Morady F: Catheter ablation for paroxysmal atrial fibrillation: segmental pulmonary vein ostial ablation versus left atrial ablation. Circulation 2003, 108:2355 2360.

6. Cappato R, Calkins H, Chen SA, Davies W, lesaka Y, Kalman J, Kim YH, Klein G, Natale A, Packer D, Skanes A: Prevalence and causes of fatal outcome in catheter ablation of atrial fibrillation. J Am Coll Cardiol 2009, 53(19):1798 1803.

7. Kannel WB, Wolf PA, Benjamin EJ, Levy D: Prevalence, incidence, prognosis, and predisposing conditions for atrial fibrillation: populationbased estimates. Am J Cardiol 1998, 82:2N 9N.

8. Gjesdal K, Vist GE, Bugge E, Rossvoll O, Johansen M, Norderhaug I, Ohm OJ: Curative ablation for atrial fibrillation: a systematic review. Scand Cardiovasc J 2008, 42(1):3 8.

9. Noheria A, Kumar A, Wylie JV Jr, Josephson ME: Catheter ablation vs antiarrhythmic drug therapy for atrial fibrillation: a systematic review. Arch Intern Med 2008, 168(6):581 586.

10. January CT, Wann LS, Alpert JS, Calkins H, Cleveland JC Jr, Cigarroa JE, Conti JB, Ellinor PT, Ezekowitz MD, Field ME, Murray KT, Sacco RL, Stevenson WG, Tchou PJ, Tracy CM, Yancy CW: 2014 AHA/ACC/HRS Guideline for the Management of Patients With Atrial Fibrillation: Executive Summary: A Report of the American College of Cardiology/American Heart Association Task Force on Practice Guidelines and the Heart Rhythm Society. J Am Coll Cardiol 2014, 64(21):2246 80.

11. Sorajja P, Cabalka AK, Hagler DJ, Rihal CS: The learning curve in percutaneous repair of paravalvular prosthetic regurgitation: an analysis of 200 cases. JACC Cardiovasc Interv 2014, 7(5):5219.

12. Hussein AA, Wazni OM, Harb S, Joseph L, Chamsi-Pasha M, Bhargava M, Martin DO, Dresing T, Callahan T, Kanj M, Natale A, Lindsay BD, Saliba WI: Radiofrequency ablation of atrial fibrillation in patients with mechanical mitral valve prostheses safety, feasibility, electrophysiologic findings, and outcomes. J Am Coll Cardiol 2011, 58(6):596 602.
13. Lakkireddy D, Nagarajan D, Di Biase L, Vanga SR, Mahapatra S, Jared Bunch T, Day JD, Burkhardt DJ, Umbarger L, Dendi R, Pimentel R, Berenbom L, Emert M, Gerken A, Bommana S, Ray W, Atkins D, Murray C, Dawn B, Natale $A$ : Radiofrequency ablation of atrial fibrillation in patients with mitral or aortic mechanical prosthetic valves: a feasibility, safety, and efficacy study. Heart Rhythm 2011, 8(7):975 980.

doi:10.1186/s13019-014-0187-4

Cite this article as: Gurbuz et al:: Case report: paravalvular leak as a complication of percutaneous catheter ablation for atrial fibrillation. Journal of Cardiothoracic Surgery 2014 9:187.

\section{Submit your next manuscript to BioMed Central and take full advantage of:}

$\bowtie$ Convenient online submission

$\otimes$ Thorough peer review

$\nabla$ No space constraints or color $\nabla$ gure charges

$\otimes$ Immediate publication on acceptance

\Inclusion in PubMed, CAS, Scopus and Google Scholar

$\nabla$ Research which is freely available for redistribution

Submit your manuscript at www.biomedcentral.com/submit
C) BioMed Central 